\title{
Impact of Alkali Concentration and Metakaolin Content on Accelerated Ageing of Egyptian Slag
}

\author{
Hamdy Abd El-Aziz Abdel Gawwad ${ }^{1}$, Hesham Mohamed Khater ${ }^{1}$, \\ Saleh Abd El-Aleem Mohamed ${ }^{2, *}$ \\ ${ }^{1}$ Housing and Building National Research Center, Giza, Egypt \\ ${ }^{2}$ Chemistry Department, Faculty of Science, Fayoum University, Fayoum, Egypt
}

Email address:

saa09@fayoum.edu.eg (S. Abd. El-Aleem Mohamed), hamdyabdelgawwad@yahoo.com (H. A. El-Aziz Abdel Gawwad)

\section{To cite this article:}

Hamdy Abd El-Aziz Abdel Gawwad, Hesham Mohamed Khater, Saleh Abd El-Aleem Mohamed. Impact of Alkali Concentration and Metakaolin Content on Accelerated Ageing of Egyptian Slag. American Journal of Chemical Engineering. Vol. 3, No. 3, 2015, pp. 30-38. doi: 10.11648/j.ajche.20150303.11

\begin{abstract}
The present work aims to study the coupled effect of alkali concentration and metakaolin (MK) on the resistivity of ground granulated blast-furnace slag (GGBFS) to strength regression during ageing. GGBFS was activated by 6 and 10 wt., $\%$ containing mixture of sodium hydroxide (SH) and liquid sodium silicate (LSS) at a ratio of 1:1, respectively (namely GGBFS $_{6}$ and $\mathrm{GGBFS}_{10}$ ). On the other hand, GGBFS 10 was replaced by 10, 20, 30, 40 and 50 wt., \% of MK, respectively. All hardened specimens were cured in $100 \%$ relative humidity (RH) at $37 \pm 2^{\circ} \mathrm{C}$ for 28 days (zero time) then, aged at $95^{\circ} \mathrm{C}$ for 56 days. Experimental results showed that, the $\mathrm{pH}$ value of alkali activated samples (AAS) decreased as the amount of MK increased. Also, the $\mathrm{pH}$ of AAS derived from $\mathrm{GGBFS}_{10}$ was higher than that of $\mathrm{GGBFS}_{6}$. The strength regression resistivity (SRR) during accelerated ageing enhanced with the decrease of alkali concentration. The compressive strength for different investigated mixes was evaluated. Also, some selected hydration products were analyzed using infrared spectroscopy (FTIR), thermogravimetric analysis (TG/DTG) and X- ray diffraction (XRD) techniques to determine the mineralogical phase transition. The results of mechanical properties are in a good agreement with those of FTIR, TG/DTG and XRD techniques and confirm that the SRR during ageing increases with MK content.
\end{abstract}

Keywords: Accelerated Ageing, GBFS, MK, Compressive Strength Regression, $\mathrm{pH}$

\section{Introduction}

In recent years, ground granulated blast-furnace slag (GGBFS) is commonly used to produce low cost, durable, and high performance concrete (HPC) by replacement portion of cement [1-4]. Many authors mixed GGBFS with alkaline solutions to produce alkali activated slag binder with excellent compressive strength and fire-resistance capability [5-12]. However, previous works showed that, the significant factors, which affect the mechanical properties of aluminosilicate based geopolymers were the liquid to solid ratio and the amount of alkaline solution $[13,14]$. El Didamony et al. [15] reported that, the optimum percentage of activator (sodium hydroxide: SH \& liquid sodium silicate: LSS), which gave the higher physico-chemical and mechanical properties was 3\% SH $+3 \%$ LSS by weight of GGBFS, also, the GGBFS activated with this amount of alkali gave higher resistivity against sea water up to one year [16]. Brough et al.
[17] concluded that, the high amount of alkali hydroxide concentration can significantly increases the strength and shorten the setting time, but it was liable to let the specimen becoming brittle and vulnerable to weathering. This problem can be improved by adding another mineral admixture or curing in water [18].

Accelerated aging testing was done under vigorous conditions of heat, oxygen, sunlight, vibration, etc. in order to speed up the normal curing process. It is used for determining long term effects of expected levels of stress within a shorter time, usually in a laboratory by controlled standard test methods. According to Provis and van Deventer [19] there are several aspects to achieve the best performance of aged geopolymer cement in a short period of time, (i) the geopolymer specimens should be cured, to allow normal microstructure development as far as possible, for sufficient time before beginning accelerated ageing; (ii) a relatively high temperature should be used; and (iii) the geopolymer 
specimens must be maintained in a closed system to prevent atmospheric carbonation, moisture loss and leaching of pore fluid.

The ageing of geopolymer prepared from metakaolin (MK), fly ash (FA), GBFS, and mixture of FA/GGBFS were studied by Provis and van Deventer [20]. They found that, a significant increase in the compressive strength of MKgeopolymer mortar cured and aged at $23^{\circ} \mathrm{C}$ up to 3 days followed by modest decline in strength after 28 days of ageing. On the other hand, the compressive strength of MKbased geopolymer, with $\mathrm{Si} / \mathrm{Al}$ ratio of 2 , normally cured at $23^{\circ} \mathrm{C}$ and aged at $95^{\circ} \mathrm{C}$ significantly increased after one day, then dramatically reduced after 3 days of ageing. The reduction in compressive strength was ascribed to the formation of a new crystalline phase of Zeolite Na-P1 $\left(\mathrm{Na}_{6} \mathrm{Al}_{6} \mathrm{Si}_{10} \mathrm{O}_{32}\right)$, sodium Chabazite $\left(\mathrm{NaAlSi}_{2} \mathrm{O}_{6} \cdot 3 \mathrm{H}_{2} \mathrm{O}\right)$. Also, they reported that, the compressive strength of FAgeopolymer with high calcium content increased after one day of ageing at $95^{\circ} \mathrm{C}$ with very little change for next 27 days Meanwhile, FA-geopolymer specimens with low calcium content changed significantly over 28 days of ageing. The compressive strength of specimens containing 100\% GGBFS after the first day of ageing was slightly reduced. Furthermore, FA- based geopolymers has better resistance to ageing than that of alkali activated slag mortars. The X-ray diffraction of geopolymer prepared from low calcium FA showed the development of Faujasite $\left(\mathrm{Na}_{2} \mathrm{Al}_{2} \mathrm{Si}_{2.4} \mathrm{O}_{8.8}\right)$ and Na-P during ageing at $95^{\circ} \mathrm{C}$. The geopolymer composed of GGBFS and FA showed no trace of Zeolites after 28 days of ageing at $95^{\circ} \mathrm{C}$. They found that, the Zeolites crystallization inhibited by the presence of calcium in geopolymer system. The effect of alkali concentration on the zeolite crystallinity, in geopolymer prepared from FA, and strength regression resistivity (SRR) during ageing was studied by the same authors; they concluded that, the SRR parallel with Zeolite P crystallization were occurred with the increase of alkali concentration in FA geopolymer. Coupled effect of alkali concentration and $\mathrm{MK}, \%$ on the resistivity of GGBFS to strength regression during ageing was not studied.

In the present investigation, an experimental work was performed to study the dual effect of alkali concentration and MK content on accelerated ageing of GGBFS at $95^{\circ} \mathrm{C}$ for 56 days, in order to elucidate the optimum alkali concentration and MK content that can resist the strength regression during ageing.

\section{Experimental Techniques}

\subsection{Materials}

The materials used in this work were GGBFS, kaolinitic clay $(\mathrm{K})$, sodium hydroxide $(\mathrm{SH})$ and liquid sodium silicate (LSS). GGBFS was provided by Iron and Steel Company, Helwan, Giza Governorate, Egypt. Kaolinitic clay was supplied from south Sinai, Governorate, Egypt. Sodium hydroxide with purity of $99.99 \%$ was obtained from SHIDO Company, UK. Commercial LSS with $32 \% \mathrm{SiO}_{2}, 11 \% \mathrm{Na}_{2} \mathrm{O}$ and density of $1.46 \mathrm{~g} / \mathrm{cm} 3$ purchased from El Gomhouryia Chemical Company, Egypt. The chemical analyses of GGBFS, MK and K obtained by X-ray fluorescence (XRF) spectrometry are listed in Table (1). The amorphous structure of GGBFS was confirmed by using XRD in Fig. (1). In contrast with the vitreous nature of GGBFS, the crystallinity of K, referring to kaolinite and quartz (Q) is shown in Fig. (2). The Kaolinite peaks disappeared as a result of kaolinitic clay calcination at $800^{\circ} \mathrm{C}$ for $4 \mathrm{hrs}$ with calcination rate of $5^{\circ} \mathrm{C} / \mathrm{min}$. The particle size distribution of GGBFS and MK are shown in Fig. (3). It is clear that, the main particle size of GGBFS and MK are $<50 \mu \mathrm{m}$ and $<40 \mu \mathrm{m}$, respectively. The mix composition of GGBFS/MK is given in Table (2). The mole oxide ratios of alkali activated samples (AAS), whether derived from GGBFS or GGBFS/MK, have been listed in Table (3).

Table 1. Chemical analyses of GGBFS, $K$ and $M K$, wt. \%

\begin{tabular}{lllllllllllll}
\hline Oxide, $\%$ & $\mathbf{S i O}_{2}$ & $\mathrm{Al}_{2} \mathbf{O}_{3}$ & $\mathbf{F e}_{2} \mathbf{O}_{3}$ & $\mathbf{C a O}$ & $\mathbf{M g O}$ & $\mathbf{N a}_{2} \mathbf{O}$ & $\mathbf{K}_{2} \mathbf{O}$ & $\mathbf{S O}_{3}$ & $\mathbf{T i O}_{2}$ & $\mathbf{P}_{2} \mathbf{O}_{5}$ & L.O.I & Total \\
\hline GGBFS & 37.81 & 13.14 & 0.23 & 38.70 & 7.11 & 1.03 & 0.19 & 1.19 & 0.40 & 0.17 & 0.56 & 99.97 \\
MK & 59.13 & 35.33 & 0.89 & 0.43 & 0.13 & 0.05 & 0.05 & 0.03 & 2.46 & 0.72 & 0.79 & 100.00 \\
K & 56.38 & 27.61 & 1.32 & 0.18 & 0.06 & 0.08 & 0.04 & 0.06 & 3.73 & 0.13 & 10.17 & 99.97 \\
\hline
\end{tabular}

Table 2. Mix composition of GGBFS or GGBFS-MK mixes.

\begin{tabular}{|c|c|c|c|c|c|}
\hline $\mathbf{W} / \mathbf{b}$ & LSS wt. \% & SH, wt.\% & GBFS, wt. \% & MK, wt. \% & Mix. Symbol \\
\hline 0.25 & 3 & 3 & 100 & 0 & I \\
\hline 0.25 & 5 & 5 & 100 & 0 & II \\
\hline 0.27 & 5 & 5 & 90 & 10 & III \\
\hline 0.29 & 5 & 5 & 80 & 20 & IV \\
\hline 0.31 & 5 & 5 & 70 & 30 & V \\
\hline 0.33 & 5 & 5 & 60 & 40 & VI \\
\hline 0.35 & 5 & 5 & 50 & 50 & VII \\
\hline
\end{tabular}


Table 3. Oxides mole ratios for one $\mathrm{kg}$ of reactant mixture.

\begin{tabular}{|c|c|c|c|c|c|c|}
\hline $\mathrm{MgO} / \mathrm{Al}_{2} \mathrm{O}_{3}$ & $\mathrm{H}_{2} \mathrm{O} /\left(\mathrm{Na}_{2} \mathrm{O}, \mathrm{K}_{2} \mathrm{O}\right)$ & $\mathrm{CaO} / \mathrm{SiO}_{2}$ & $\left(\mathrm{Na}_{2} \mathrm{O}, \mathrm{K}_{2} \mathrm{O}\right) / \mathrm{SiO}_{2}$ & $\left(\mathrm{Na}_{2} \mathrm{O}, \mathrm{K}_{2} \mathrm{O}\right) / \mathrm{Al}_{2} \mathrm{O}_{3}$ & $\mathrm{SiO}_{2} / \mathrm{Al}_{2} \mathrm{O}_{3}$ & Mix symbol \\
\hline 1.37 & 20.13 & 1.07 & 0.11 & 0.54 & 5.01 & I \\
\hline 1.37 & 14.23 & 1.05 & 0.15 & 0.76 & 5.09 & II \\
\hline 1.06 & 15.78 & 0.90 & 0.14 & 0.63 & 4.59 & III \\
\hline 0.82 & 17.40 & 0.76 & 0.13 & 0.54 & 4.22 & IV \\
\hline 0.64 & 19.11 & 0.64 & 0.12 & 0.46 & 3.93 & $\mathrm{~V}$ \\
\hline 0.50 & 20.92 & 0.52 & 0.11 & 0.41 & 3.70 & VI \\
\hline 0.38 & 22.84 & 0.42 & 0.10 & 0.36 & 3.51 & VII \\
\hline
\end{tabular}

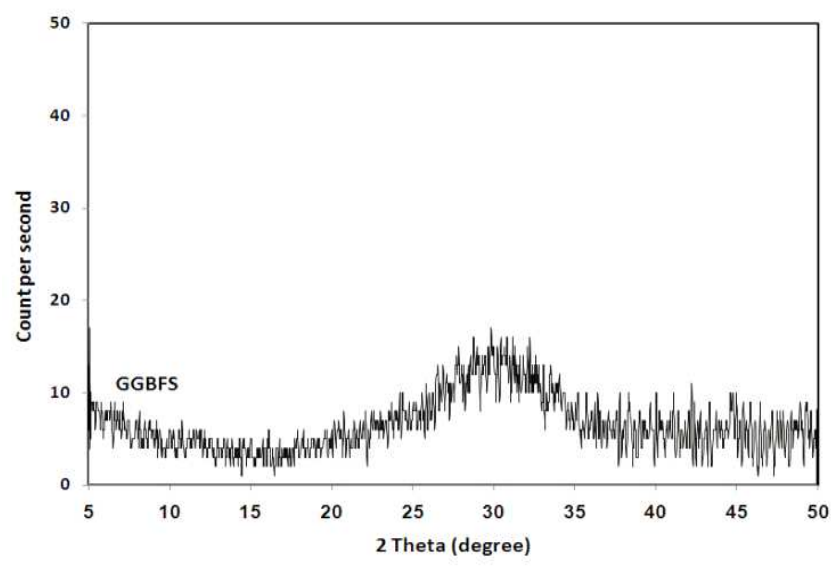

Fig. 1. XRD pattern of $G G B F S$

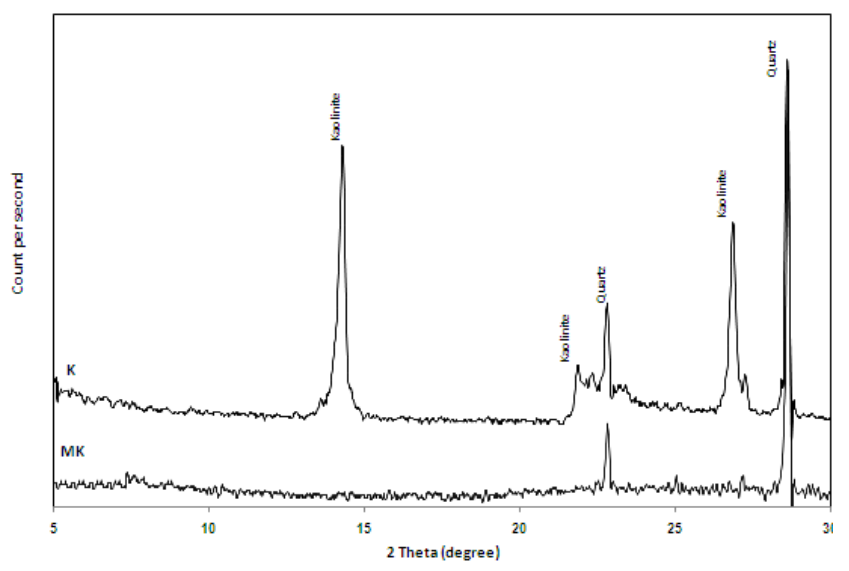

Fig. 2. XRD pattern of kaolin (K) and metakaolin (MK)

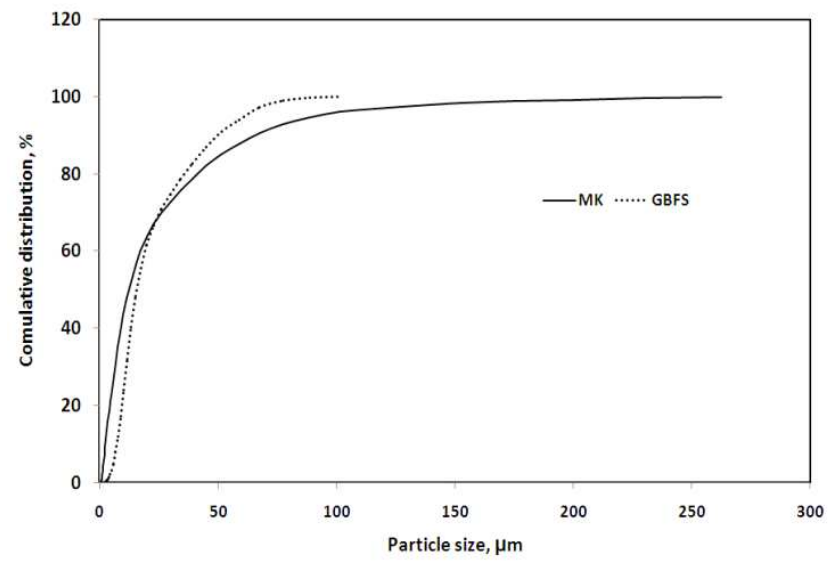

Fig. 3. Particle size distribution of GGBFS and $M K$

\subsection{Preparation of Alkali Activated Paste}

For the preparation of the paste samples, the GGBS and MK were mixed by hand in a bowl followed by 5 minutes' dry mixing in a mixer to which the SH and LSS solution was then added. The mixer was stopped after 3 minutes of slow mixing, to collect any unmixed solids scraped from the sides of the mixing bowl and the paddle into the bowl, and then slow mixing for 2 minutes and fast mixing for 5 minutes were applied to ensure homogeneity. For each mix, the freshly mixed cement paste was placed into one inch cubic mould and vibrated using vibration machine for one min, then the surface smoothed by a thin edged trowel. After moulding the specimens were cured in $100 \%$ relative humidity (R.H.) for $24 \mathrm{hrs}$ at $37 \pm 2{ }^{\circ} \mathrm{C}$ [15], [16], then demoulded and cured in humidifier at the same condition for 28 days (zero time). Two alkali activated slag series mixes were prepared using 6 and $10 \mathrm{wt}$. $\%$ of SH\&LSS mixture at a ratio of 1:1 (namely GGBFS 6 and GGBFS 10 ). Five GGBFS $_{10^{-}}$ MK pastes in which GGBFS-MK activated by 10 wt., $\%$ of SH\&LSS (namely GGBFS $_{10} / \mathrm{MK}$ ) were prepared at different water/binder (W/b) ratios as given in Table (2).

\subsection{Accelerated Ageing Test}

After curing GGBFS $_{6}$, GGBFS $_{10}$ or $\mathrm{GGBFS}_{10} / \mathrm{MK}$ specimens in humidifier in $100 \%$ R.H., at $37 \pm 2^{\circ} \mathrm{C}$ for 28 days, the specimens were transferred to an oven of $95^{\circ} \mathrm{C}$ and remained until the time testing $(1,3,7,14,28$ and 56 days ) [19].

\subsection{Methods of Investigation}

The $\mathrm{pH}$ of AAS was determined by dissolving $5 \mathrm{~g}$ of powdered AAS, with main particle size of $45 \mu \mathrm{m}$, in $50 \mathrm{ml}$ of de-ionized water, kept for 24 hrs., then the suspension was measured by $\mathrm{pH}$ electrode [21]. The compressive strength was recorded after 1, 3, 7, 14, 28, 56 days according to ASTM C109M [22]. A compressive test was carried out in a hydraulic universal testing machine (3R), Germany, of a 150.0 MPa capacity. Thermogravimetric analysis (TGA) was carried out by heating the sample in nitrogen atmosphere up to $1000^{\circ} \mathrm{C}$ with a heating rate of $20^{\circ} \mathrm{C} / \mathrm{min}$ using a DT-50 Thermal Analyzer (Schimadzu Co-Kyoto, Japan). X-ray diffraction analysis was carried out using a Philips PW $3050 / 60$. The infrared spectral analysis was recorded from $\mathrm{KBr}$ discussing Genesis-IIFT-IR spectrometer in the range of $400-4000 \mathrm{~cm}^{-1}$. 


\section{Results and Discussion}

\section{1. pH Measurement}

Fig. (4) shows the $\mathrm{pH}$ values of cured AAS prepared from GGBFS $_{6}$ (I) GGBFS 10 (II), 90/10 (III), 80/20 (IV), 70/30 (V), $60 / 40$ (VI) and 50/50 (VII) $\mathrm{GGBFS}_{10} / \mathrm{MK}$, at 28days (zero time). It can be seen that, the $\mathrm{pH}$ of alkali activated $\mathrm{GGBFS}_{6}$ is lower than that of $\mathrm{GGBFS}_{10}$. The replacement of $\mathrm{GGBFS}_{10}$ by $\mathrm{MK}$ decreases the $\mathrm{pH}$ value. These facts may be related to the amount of free sodium oxide, which decreases with the decrease of the alkali activator and increase of the replacement level of $\mathrm{GGBFS}_{10}$ by MK.

The amount of alkali activators in geopolymer $\mathrm{GGBFS}_{6}$ is sufficient to activate GGBFS portion with no free alkali in AAS, whereas in case of $\mathrm{GGBFS}_{10}$, the free sodium oxide remains in AAS, causing increase of $\mathrm{pH}$ value. Furthermore, sodium cations $\left(\mathrm{Na}^{+}\right)$in case of $\mathrm{GGBFS}_{10}$ or $\mathrm{GGBFS}_{6}$ are not attached chemically or trapped physically in alkali activated system but located at non bridging oxygen site $\mathrm{Si}-\mathrm{O}^{-} \mathrm{Na}^{+}$or $\mathrm{Al}-\mathrm{O}^{-} \mathrm{Na}^{+}$which may moves to form $\mathrm{NaOH}$. Meanwhile, in case of $\mathrm{GGBFS}_{10} / \mathrm{MK}$, the Na cations are trapped within the alkali activated system, which provide long-term stability and decrease the leachability of alkali to the medium [23]. In addition, the mole ratios of $\left(\mathrm{Na}_{2} \mathrm{O}, \mathrm{K}_{2} \mathrm{O}\right) / \mathrm{Al}_{2} \mathrm{O}_{3}$ and $\left(\mathrm{Na}_{2} \mathrm{O}, \mathrm{K}_{2} \mathrm{O}\right) / \mathrm{SiO}_{2}$ decrease with the increase of replacement level of GGBFS10 by MK as given in Table (3).

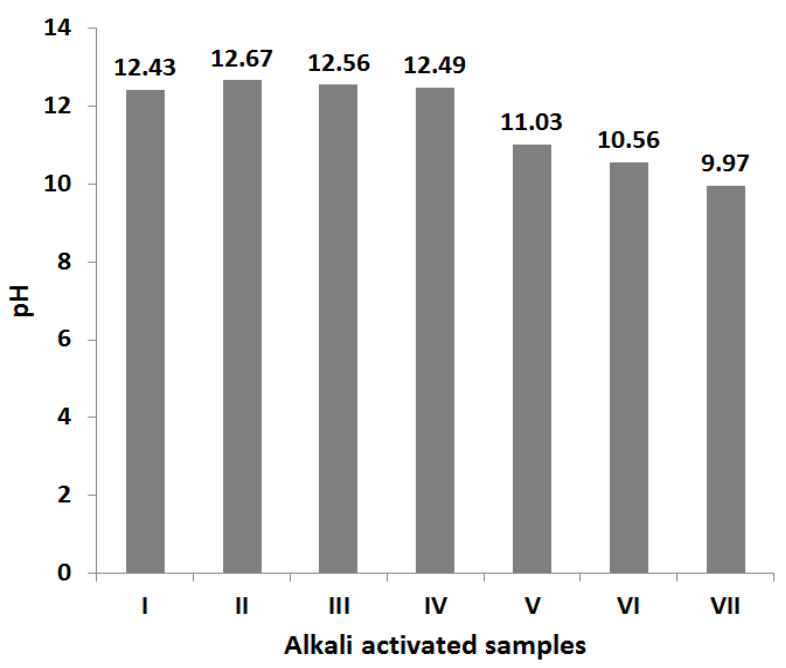

Fig. 4. $p H$ values of the geopolymer samples at zero time.

\subsection{Compressive Strength}

The values of compressive strength of all investigated mixtures at 28 days (zero time) of curing in $100 \% \mathrm{RH}$ at 37 $\pm 2{ }^{\circ} \mathrm{C}$ and aged at $95^{\circ} \mathrm{C}$ for $1,3,7,14,28$ and 56 days are graphically represented in Fig. (5). It is clear that, the highest value of compressive strength at zero time was observed in GGBFS $_{10}$ replaced by 10 (III) and 20 (IV) wt., \% of MK, respectively. The compressive strength alkali activated $\mathrm{GGBFS}_{10}$ (II) is lower than that of $\mathrm{GGBFS}_{6}$ (I) at zero time. The replacement of $\mathrm{GGBFS}_{10}$ with 30 (V), 40 (VI), and 50 (VII) wt., $\%$ of MK reduces the compressive strength by $\sim 46$,
55 , and $67 \%$ at zero time, respectively. The $\mathrm{GGBFS}_{10}$ shows a dramatic reduction in strength after 14 days of ageing at $95^{\circ} \mathrm{C}$. Meanwhile, the alkali activated $\mathrm{GGBFS}_{6}$ shows a significant increase in compressive strength after one day of ageing, and then exhibits a slight decrease in compressive strength after 3 days of ageing. The results of GGBFS ${ }_{6}$ are in a good harmony with those of a previous work [22]. The compressive strength of alkali activated GGBFS $_{10}$ reduces by $\sim 33 \%$ after 14 days of ageing as compared with that at zero time, then remained stable after the next 42 days. The compressive strength values of alkali activated $\mathrm{GGBFS}_{10} / \mathrm{MK}$ increases after 1 day, and then remained constant for the next 55 days of ageing.

Finally, the compressive strength reduction of alkali activated $\mathrm{GGBFS}_{10}$ at zero time is due to that, the dissolution/condensation rates increase with the increase of alkali concentration until the optimum concentration is reached, and then the two processes are hindered [20]. The compressive strength regression of $\mathrm{GGBFS}_{10}$ aged at $95^{\circ} \mathrm{C}$ may be explained by the presence of higher amount of free $\mathrm{Na}_{2} \mathrm{O}$ in cement matrix. According to Shi et al. [24], free $\mathrm{Na}_{2} \mathrm{O}$ interacts $\mathrm{CSH}$ at room or elevated temperatures by different three mechanisms; the first mechanism is the neutralization of acidic $\mathrm{Si}-\mathrm{OH}$ group by $\mathrm{Na}^{+}$to form $\mathrm{Na}-\mathrm{C}-\mathrm{S}-\mathrm{H}$, while the second is the ion exchange of $\mathrm{Na}^{+}$for $\mathrm{Ca}^{2+}\left(\mathrm{Na}^{+}+\mathrm{C}-\mathrm{S}-\mathrm{H} \rightarrow \mathrm{Na}^{+}-\mathrm{C}-\mathrm{S}-\mathrm{H}+\mathrm{Ca}^{2+}\right)$ and the third is the cleavage of $\mathrm{Si}-\mathrm{O}-\mathrm{Si}$ bonds by $\mathrm{Na}^{+}\left(\mathrm{Si}-\mathrm{O}-\mathrm{Si}+\mathrm{Na}^{+} \rightarrow\right.$ $2 \mathrm{Si}-\mathrm{OM})$. In the obove mentioned michanisms, the binding capacity of $\mathrm{CSH}$ is breakdown, leading to adhesion and strength reductions [20], [25]. The compressive strength development and SRR during ageing of GGBFS $_{10}$ samples containing 10 or 20 wt., $\% \mathrm{MK}$ are ascribed to the neutralization of free sodium cations by MK [23].

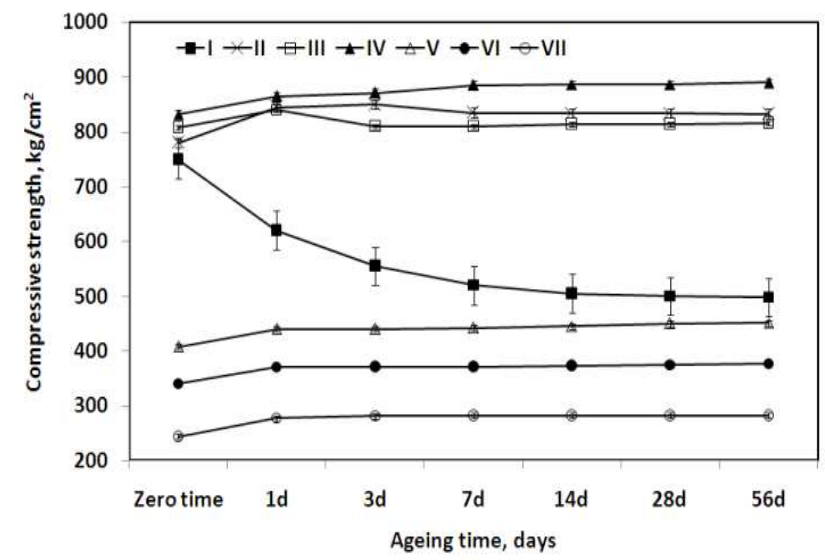

Fig. 5. Compressive strength of cured samples at 28 days (zero time) and ageing at $95^{\circ} \mathrm{C}$ up to 56 days.

The replacement of $\mathrm{GGBFS}_{10}$ with 30,40 and 50 wt., \% MK reduces the strength of cured sample at zero time, whereas at long-term, the durability and stability to strength regression during ageing at $95^{\circ} \mathrm{C}$ is enhanced. The results are in a good agreement with the previous findings by Davidovits [23], which states that, the three dimensions (3D) aluminosilicate geopolymer will occur when GGBFS 
replaced by higher amount of MK, which decreases the compressive strength, while it has long-term stability and durability.

\subsection{FTIR Spectroscopy}

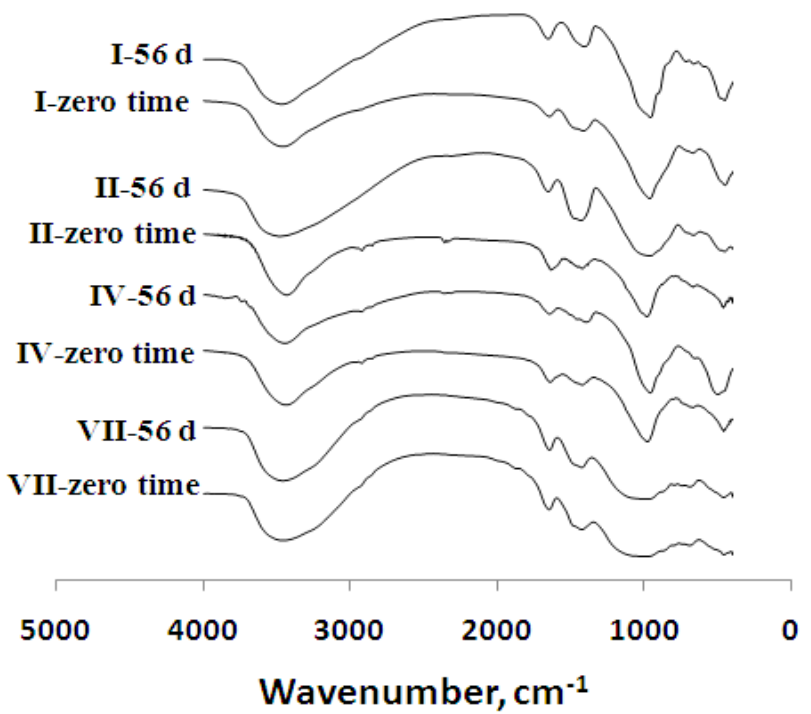

Fig. 6. FTIR spectra of different mixes at zero time as well as 56 days of ageing.

Figure (6) represents the FTIR spectra of different AAS; GGBFS6 (I), GGBFS10 (II), 80/20 (IV), and 50/50 (VII) GGBFS10/MK at zero time as well as 56 days of ageing. The comparison between geopolymer samples will be focused on the main absorption band at $937-960 \mathrm{~cm}^{-1}$ related to asymmetric stretching vibration of $\mathrm{T}-\mathrm{O} \mathrm{Si}$ (where $\mathrm{T}$ means $\mathrm{Si}$ or $\mathrm{Al}$ ). The wider the asymmetric band at full width at half maximum (FWHM), the more disordered structure; where asymmetric absorption band at $960 \mathrm{~cm}^{-1}$ of $\mathrm{GGBFS}_{10}$ aged at $95^{\circ} \mathrm{C}$ for 56 days is wider than that at zero time. This may be related to the cleavage of $\mathrm{T}-\mathrm{O} \mathrm{Si}$ by free alkali hydroxide to form $\mathrm{Si}-\mathrm{OH}$ group [24], [26], leading to significant fluctuation of geometric parameters causing the formation of disordered structure [6].

This confirms the compressive strength regression of GGBFS $_{10}$ during ageing process. Also, the results of FTIR spectra show that, there is no change in the FWHM of asymmetric absorption bands of $\mathrm{GGBFS}_{6}(\mathrm{I})$ at zero time and 56 days of ageing, proving resistivity of $\mathrm{GGBFS}_{6}$ to strength regression during ageing. The intensity of absorption band at $954 \mathrm{~cm}^{-1}$ of alkali activated $\mathrm{GGBFS}_{10}$ replaced by $20 \mathrm{wt}$., $\%$ $\mathrm{MK}$ at zero time is higher than that of $\mathrm{GGBFS}_{10}$ at the same time. The absorption band, at $937 \mathrm{~cm}^{-1}$, of AAS containing of 20 wt., $\%$ of $\mathrm{MK}$ aged at $95^{\circ} \mathrm{C}$ for 56 days is more intense than that of the same AAS at zero time of ageing. These facts confirm that, the compressive strength and SRR during accelerated ageing are enhanced by replacement of GGBFS by 20 wt., $\%$ MK. The absorption band related to $\mathrm{Si}-\mathrm{O}-\mathrm{Si}$ asymmetric stretching vibration of crystalline quartz at about $1100 \mathrm{~cm}^{-1}$ appears when GGBFS replaced by $50 \mathrm{wt}$., $\% \mathrm{MK}$. The band intensity of $\mathrm{T}-\mathrm{O}-\mathrm{Si}$ related to asymmetric stretching vibration of the AAS containing $50 \mathrm{wt}$., \% MK is lower than that containing 0 and 20 wt., \% MK, which confirms the compressive strength values.

\subsection{TG/DTG Analysis}

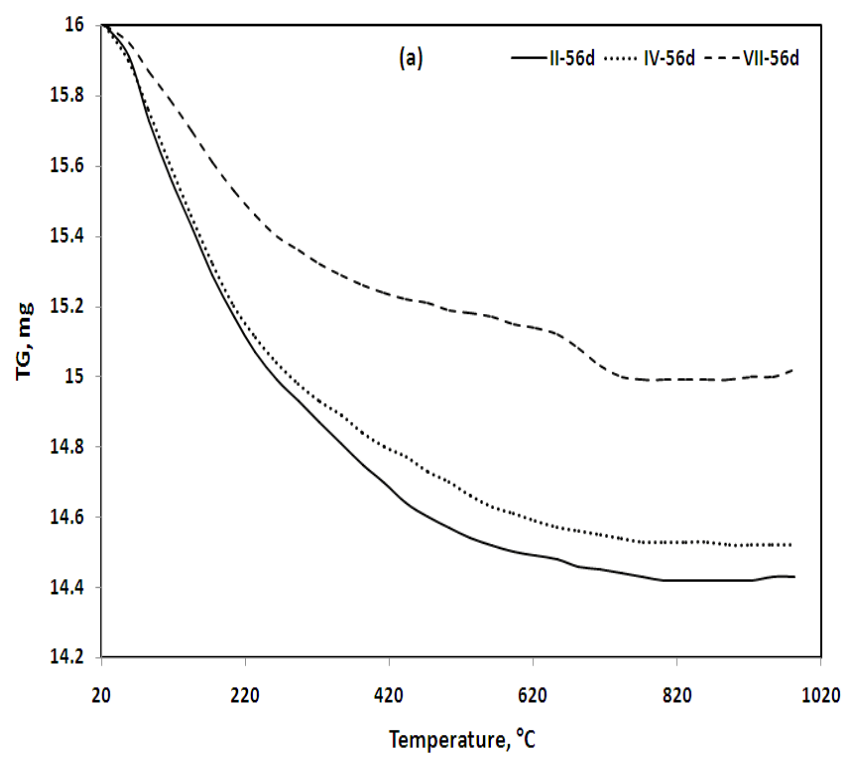

Fig. 7 (a). TG-Thermograms of $G B B F S_{6}(I I)$ or $G G B F S_{10} / M K$ at ratios of $80 / 20$ (IV) and 50/50 (VII) at zero time.

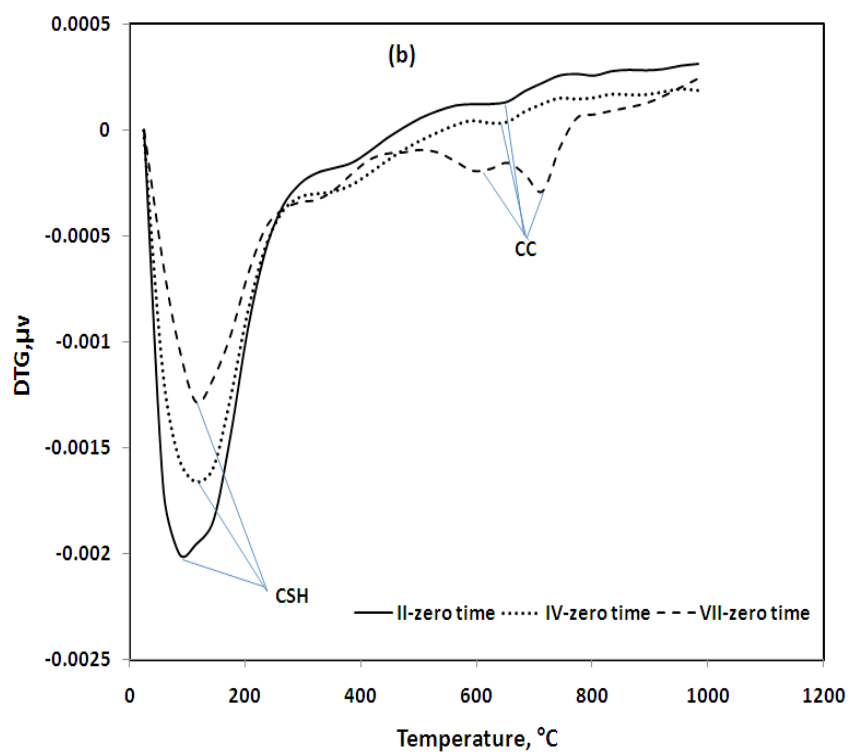

Fig. 7 (b). DTG-Thermograms of $\mathrm{GBBFS}_{6}$ (II) or $G G B F S_{10} / M K$ at ratios of $80 / 20$ (IV) and 50/50 (VII) at zero time.

Fig. 7 (a \& b) shows TG/DTG thermogram of alkali activated $\mathrm{GGBBFS}_{10}, \mathrm{GGBFS}_{10} / \mathrm{MK}$ at ratios of $80 / 20$ (IV) and 50/50 (VII) at zero time. The TG/DTG indicated that, the weight losses of the investigated AAS are 10.38, 8.60 and $6.63 \%$ for mixes II, IV and VII, respectively.

The endothermic peak of CSH in mix II is more intense than that of CSH in the mixes IV and VII. This is attributed to the decrease of calcium cations with MK content, which can be observed from $\mathrm{CaO} / \mathrm{SiO}_{2}$ ratio in Table (3). The $\mathrm{CSH}$ peaks are shifted to higher temperatures with $\mathrm{MK} \%$, which 
explained by the formation of $\mathrm{CSH}$ (I) with low $\mathrm{Ca} / \mathrm{Si}$ ratio that decomposed at higher temperature than that of CSH (II) with high $\mathrm{Ca} / \mathrm{Si}$ ratio. Alkali activated $\mathrm{GGBFS}_{10}$ containing 50 wt., \% MK shows the highest atmospheric carbonation, which explains its higher porosity and lower strength.

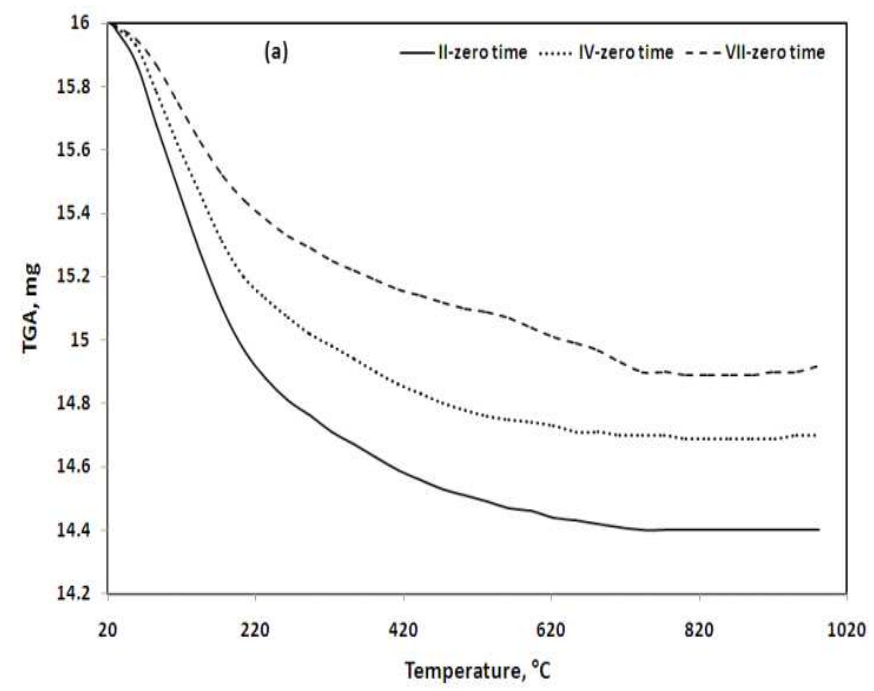

Fig. 8 (a). TGA-Thermograms of $G B B F S_{6}(I I)$ and $G G B F S_{10} / M K$ at ratios of $80 / 20$ (IV) and 50/50 (VII) at 56 days of ageing.

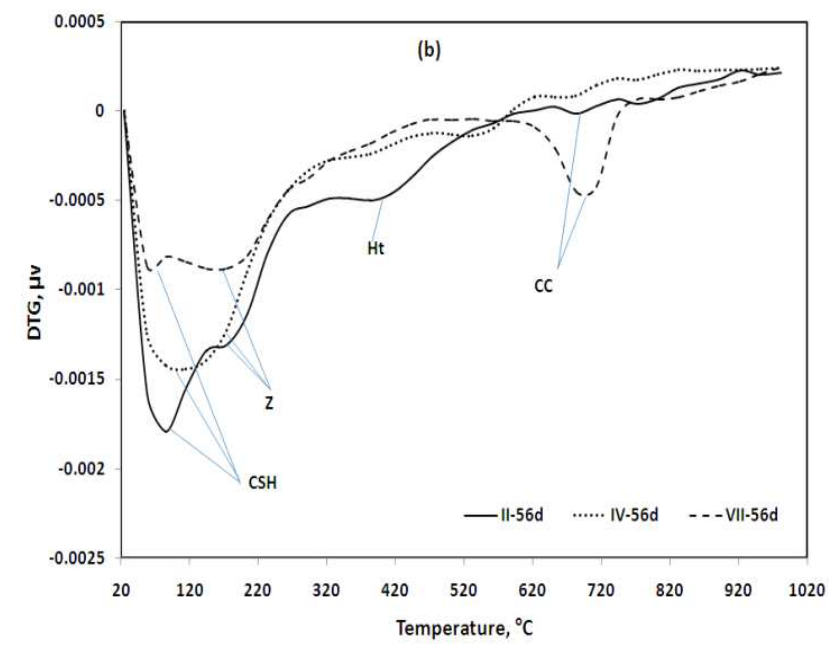

Fig. 8 (b). DTG-Thermograms of $G B B F S_{6}(I I)$ and $G G B F S_{10} / M K$ at ratios of $80 / 20$ (IV) and 50/50 (VII) at 56 days of ageing.

Fig. 8 (a\&b) represents TG/DTG thermogram of GGBBFS $_{10}$ (II), GGBFS $10 / \mathrm{MK}$ at ratios of $80 / 20$ (IV) and $50 / 50$ (VII) after 56 days of ageing at $95^{\circ} \mathrm{C}$. It is obvious that, the weight loss of AAS increases after ageing at $95^{\circ} \mathrm{C}$ with different percentages, $10.59 \%$ for mix II, $11.03 \%$ for mix IV and $7.02 \%$ for mix VII. There is a new endothermic peaks observed at $174^{\circ} \mathrm{C}$ as a result of ageing. This peak is mainly referred to the dehydration of zeolite $(\mathrm{Z})$ type product formed along with $\mathrm{CSH}$ and CASH gel [27]. The broadness of this peak increases with MK \%, which proves the increase of zeolite with MK content. The endothermic peak observed at $383^{\circ} \mathrm{C}$ is corresponds to hydrotalcite like-phase (Ht). Its intensity decreases with the replacement of $\mathrm{GGBFS}_{10}$ by $20 \%$ $\mathrm{MK}$ and disappeared when the level of replacement reaches to $50 \%$, due to the decrease of magnesium cations with $\mathrm{MK}$ content as shown from $\mathrm{MgO} / \mathrm{Al}_{2} \mathrm{O}_{3}$ ratio in Table. (3).

\subsection{Patterns of X-ray Diffraction (XRD)}

Fig. (9) shows X-ray diffractographs of AAS prepared from $50 \%$ GGBFS10/50\% MK (VII) after 28 days of curing (zero time) as well as after 1, 28 and 56 days of ageing at $95^{\circ} \mathrm{C}$. It is clear that, no change in X-ray patterns of aged samples at 0 and one day. After 28 days of ageing, traces amount of new crystalline phases, related to the formation of zeolite Na-P1 (P1) and faujasite (F), have been observed. The amount of zeolite-P1 increases on the expense of faujasite content after 56 days of ageing.

Faujasite is metastable phase, which is transformed to zeolite-P1 at later ages of ageing [28]. It is important to note that, the amount of crystallized zeolite formed in alkali activated $\mathrm{GGBFS}_{10}-\mathrm{MK}$ in this work is lower than that in case of MK based geopolymer in previous work. The small amount of crystallized zeolite in geopolymer matrix does not cause higher compressive strength loss [19]. This is in agreement with the compressive strength results of alkali activated $\mathrm{GGBFS}_{10}-\mathrm{MK}$.

Fig. (10) represents the XRD patterns of AAS containing 100/0 (II), 90/10 (III) 80/ 20 (IV) and 50/50 (VII) $\mathrm{GGBFS}_{10} / \mathrm{MK}$ after 56 days of ageing at $95^{\circ} \mathrm{C}$. The XRD pattern of $\mathrm{GGBFS}_{10}$ is predominantly amorphous with no faujasite and zeolite-P traces. The XRD pattern indicates the decrease in the intensity of CSH peak, as the replacement of GGBFS $_{10}$ increases. Also, the Ht like-phase is observed in GGBFS $_{10}$ sample made of and disappeared in all mixes of $\mathrm{GGBFS}_{10} / \mathrm{MK}$. These facts may be related to that, the ratios of $\mathrm{CaO} / \mathrm{SiO}_{2}$ and $\mathrm{MgO} / \mathrm{Al}_{2} \mathrm{O}_{3}$ decrease with the increase of replacement level of $\mathrm{GGBFS}_{10}$ by $\mathrm{MK}$ as given in Table. (3). On the other hand, the amount of faujasite and zeolite-P1 increases with the increase of MK content. 


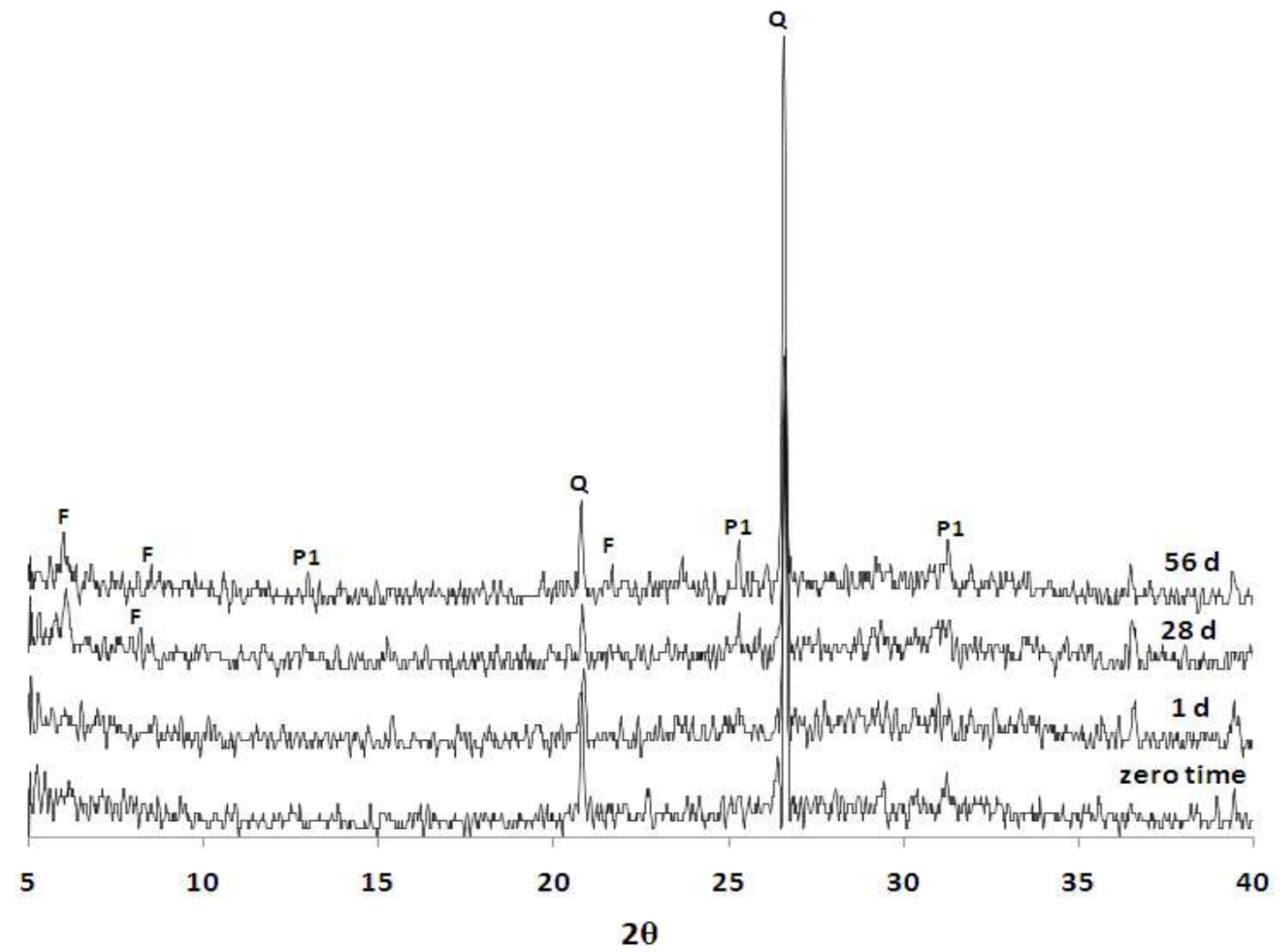

Fig. 9. X-ray diffractographs obtained for mix (VII) after 28 days of curing (zero time) as well as after 1,28 and 56 days of ageing at $95^{\circ} \mathrm{C}$

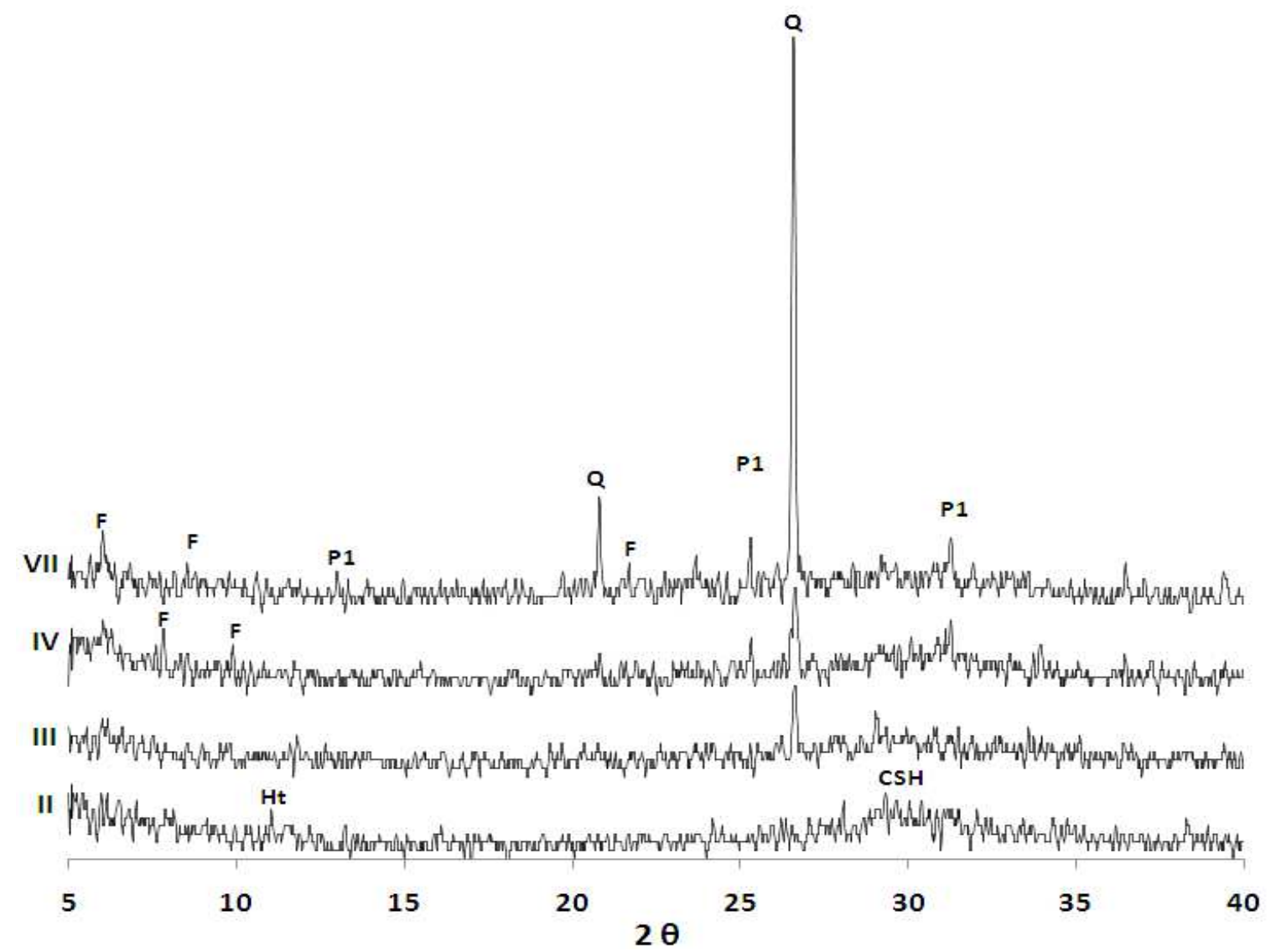

Fig. 10. X-ray diffractographs obtained for mixes II, III, IV and VII after 56 days of ageing at $95^{\circ} \mathrm{C}$. 


\section{Conclusion}

Several findings can be concluded from this work as follows:

1. As the amount of alkali concentration increases, the $\mathrm{pH}$ of AAS prepared from GGBFS increases. Furthermore, the $\mathrm{pH}$ value decreased with the increase of replacement level of $\mathrm{GGBFS}_{10}$ by MK.

2. The compressive strength of alkali activated GGBFS $_{6}$ was higher than that of $\mathrm{GGBFS}_{10}$ at zero time; meanwhile, the earlier has higher resistivity to strength regression during accelerated ageing.

3. A significant increase in the compressive strength of cured sample (zero time) was observed when GGBFS 10 was replaced by 10 and 20 wt., \% of MK. Meanwhile, the replacement of $\mathrm{GGBFS}_{10}$ with 30,40 and $50 \% \mathrm{MK}$ reduced the compressive by $\sim 46,55$, and $67 \%$ as compared with the neat $\mathrm{GGBFS}_{10}$ at zero time of ageing.

4. The resistivity to strength regression during ageing was enhanced by the replacement of GGBFS10 by MK. Furthermore, a trace amount of crystallized zeolite was observed in AAS prepared from GGBFS10/MK at later ages of accelerated ageing up to 56 days.

\section{References}

[1] S. Akyuz, A. Oner, "An experimental study on optimum usage of GGBS for the compressive strength of concrete," Journal of Cement and Concrete Composites, 29 (6), pp. 505-514, 1992.

[2] O. Boukendakdji, S. Kenai, E.H. Kadri, F. Rouis, "Effect of slag on the rheology of fresh self- compacted concrete," Journal of Construction and Building Materials, 23, (7), pp. 2593-2598, 2009.

[3] A. Nazari, S. Riahi, "The effects of $\mathrm{TiO}_{2}$ nanoparticles on physical, thermal and mechanical properties of concrete using ground granulated blast furnace slag as binder," Journal of Material Scince and Engineering, A 528 (4-5), pp. 2085-2092, 2011.

[4] E. Vejmelková, M. Keppert, S. Grzeszczyk, B. Skaliński, R. Černýa, "Properties of self-compacting concrete mixtures containing metakaolin and blast furnace slag," Journal of Construction and Building Materials, 25(3), pp. 1325-1331, 2011.

[5] C. Li, H. Sun, L. Li, "A review: The comparison between alkali-activated slag $(\mathrm{Si}+\mathrm{Ca})$ and metakaolin $(\mathrm{Si}+\mathrm{Al})$ cements," Journal of Cement and Concrete Research, 40(9), pp. 13411349,2010

[6] W. Mozgawa, J. Deja, "Spectroscopic studies of alkaline activated slag geopolymers," Journal of Molecular Structure, 924-926, pp. 434-441, 2009.

[7] J.E. Oh, P.J.M. Monteiro, S.S. Jun, S. Choi, and S.M. Clark, "The evolution of strength and crystalline phases for alkaliactivated ground blast furnace slag and fly ash-based geopolymers," Journal of Cement and Concrete Research, 40 (2), pp. 189-196, 2010.
[8] J. Temuujin, W. Rickard, M. Lee, A. Riessen, "Preparation and thermal properties of fire resistant metakaolin-based geopolymer-type coatings," Journal Non-Crystalline Solid, 357(5), pp. 1399-1404, 2010.

[9] Z. Zhang, , X. Yao, and H. Zhu, "Potential application of geopolymers asprotection coatings for marine concrete: I. Basic properties," Applied Clay Science, 49(1-2), pp. 1-6, 2010.

[10] S. Abd.El.Aleem, M. Heikal, W.M. Morsi "Hydration characteristic, thermal expansion and microstructure of cement containing nano-silica", Constr. Build. Mater.; 59, 2014, 151-160.

[11] M. Heikal, S. Abd El-Aleem, and W.M. Morsi, "Characteristics of blended cement containing ano-silica", HBRC Journal (9) (2013), pp. 243-255.

[12] M.A. Abd-El.Aziz, S. Abd.El.Aleem, and M. Heikal "Physicochemical and mechanical characteristics of pozzolanic cement pastes and mortars hydrated at different curing temperatures" Constr. Build. Mater., 26; (2012), pp. 310-316.

[13] J.G.S. van Jaarsveld, J.S.J. Van Deventer, "Effect of the alkali metal activator on the properties of fly ash-based geopolymers," Industerial. Engneering Chemical Research, 38(10), pp. 3932- 3941, 1999.

[14] H. Xu, J.S.J. Van Deventer, "The geopolymerisation of alumino- silicate minerals," International. Journal of Mineral Processing, 59 (3), pp. 247-266, 2000.

[15] ] H. El Didamony, H.H. Assal, T.M. El Sokkary, H.A. Abdel Gawwad, "Physico-chemical properties of alkali activated slag pastes," Journal of Housing and Bulding Research. Center, 6, pp. 47-55, 2010.

[16] H. El-Didamony, A.A. Amer, H. Abd El-Aziz, "Properties and durability of alkali-activated slag pastes immersed in sea water," Journal of Ceramic International, 38, pp. 3773-3780, 2012.

[17] A.R. Brough, M. Holloway, J. Sykes, A. Atkinson "Sodium silicate-based alkali-activated slag mortars: Part II. The retarding effect of additions of sodium chloride or malic acid," Journal of Cement and Concrete Research, 30 (9), pp. 1375 1379,2000

[18] Tzong-Ruey Yang, Ta-Peng Chang, Bo-Tsun, Shih Chen, Jeng-Ywan, and Wei-Lun Lin, "Effect of alkaline solutions on engineering properties of alkali-activated ggbfs paste," Journal of Marine Science and Technology, 20, (3), pp. 311-318, 2012.

[19] J.L. Provis, J.S.J vanDeventer, "Geopolymers: Structures, processing, properties and industrial applications," Accelerated ageing of geopolymers, Woodhead Publishing, Abingdon UK, pp. 139-166, 2009.

[20] J.L. Provis, J.S.J van Deventer, "Geopolymers: Structures, processing, properties and industrial applications," Geopolymer synthesis and kinetics, Woodhead Publishing, Abingdon UK, pp. 118-136, 2009.

[21] V. Räsänen, V. Penttala, "The $\mathrm{pH}$ measurement of concrete and smoothing mortar using a concrete powder suspension," Journal Cement and Concrete Research, 34 (5), pp. 813-820, 2004. 
[22] ASTM C109M, "Standard test method for compressive strength of hydraulic cement mortars," 2012.

[23] J. Davidovits, "Geopolymer chemistry and applications,", Calcium based geopolymer, Saint Quentin, France: Geopolymer Institute, $3^{\text {rd }}$ edition, pp. 201-244, 2011.

[24] Caijun Shi, V. Pavel Krivenko, Della Roy, "Alkali-Activated slag cement and concrete," Hydration and microstructure, Taylor \& Francis, USA, pp. 64-105, 2006.

[25] T. Bakharev, , J.G. Sanjayanand, Y.B. Cheng, "Sulfate Attack on Alkali Activated Slag Concrete," Journal of Cement and Concrete Research, 32, pp. 211-216, 2002.
[26] J. Davidovits, (2011b), "Geopolymer chemistry and applications," Rock based geopolymer, Saint Quentin, France: Geopolymer Institute, $3^{\text {rd }}$ edition, pp. 245-261, 2011.

[27] S.A. Bernal, E.D. Rodriguez, R. de Guierrez Mejia, M. Gordillo, J. Provis, "Mechanical and thermal characterisation of geopolymers based on silicate-activated metakaolin/slag blends," Journal of Material Scince, 46 (16), pp. 5477-5486, 2011.

[28] A. Katovic, B. Subotic, I. Smit, L.A. Despotovic, "Crystallization of tetragonal (B8) and cubic (B1) modifications of zeolite NaP from freshly prepared gel. Part I. Mechanism of crystallization," Journal of Zeolites, 9, pp. 4553, 1989. 